CZASOPISMO INŻYNIERII LĄDOWEJ, ŚRODOWISKA I ARCHITEKTURY JOURNAL OF CIVIL ENGINEERING, ENVIRONMENT AND ARCHITECTURE

JCEEA, t. XXXIII, z. 63 (3/16), lipiec-wrzesień 2016, s. 9-16

\author{
Janusz BELOK ${ }^{1}$ \\ Beata WILK-SŁOMKA ${ }^{2}$
}

\title{
WPLYW PARAMETRÓW OSZKLENIA \\ NA ZUŻYCIE ENERGII W STREFIE O REGULOWANEJ TEMPERATURZE
}

\begin{abstract}
Celem pracy było określenie wpływu parametrów oszklenia na zużycie energii w wybranej strefie cieplnej. Jako strefę o regulowanej temperaturze wybrano pomieszczenie o charakterze pokoju dziennego z aneksem kuchennym (open space), często spotykane w rozwiązaniach architektonicznych współczesnego budownictwa jednorodzinnego, energooszczędnego. Elewację południową pomieszczenia stanowi przeszklona fasada, która w założeniu miała być elementem pozyskiwania energii cieplnej z promieniowania słonecznego. Wymiary pomieszczenia wynoszą 4,0 × 6,0 m, wysokość $2,8 \mathrm{~m}$. Metoda badawcza przyjęta w pracy to badania numeryczne z wykorzystaniem programów Comfen, Window, Therm oraz EnergyPlus. Do analiz przyjęto 4 warianty. Punkt odniesienia stanowi przeszklona fasada złożona z zestawu szybowego jednokomorowego wypełnionego powietrzem. Pozostałe warianty dobrano tak, aby odpowiadały współczesnym rozwiązaniom zestawów szybowych dla budownictwa niskoenergetycznego. Spełniają one aktualne wymagania izolacyjności termicznej wg [3], przy czym różnią się wartościami współczynników: przenikania ciepła $U$, całkowitej przepuszczalności energii promieniowania słonecznego g oraz przepuszczalności światła $\tau_{\text {vis. }}$ Są to zestawy trójszybowe, w których komory wypełniono argonem, szyby pokryto powłokami selektywnymi (por. tab. 1). Dodatkowo analizowano wpływ zastosowania ruchomych żaluzji. Najbardziej korzystnymi z punktu widzenia miesięcznych zysków ciepła przez fasadę oraz zużycia energii w roku wydają się być rozwiązania W2 oraz W2_Ż czyli zestaw trójszybowy, w którym komory są wypełnione argonem, szyby pokryte powłokami niskoemisyjnymi, bez lub z żaluzjami.
\end{abstract}

Słowa kluczowe: współczynnik całkowitej przepuszczalności energii promieniowania słonecznego, zyski ciepła od promieniowania słonecznego, zestawy szybowe, powłoki niskoemisyjne, budownictwo energooszczędne

\footnotetext{
${ }^{1}$ Autor do korespondencji / corresponding author: Janusz Belok, Politechnika Śląska, Katedra Budownictwa Ogólnego i Fizyki Budowli, ul. Akademicka 5, 44-100 Gliwice; tel. 322372687; janusz.belok@polsl.pl

2 Beata Wilk-Słomka, Politechnika Śląska, Katedra Budownictwa Ogólnego i Fizyki Budowli, ul. Akademicka 5, 44-100 Gliwice; tel. 322372142; beata.wilk-slomka@polsl.pl
} 


\section{Wprowadzenie}

Na zużycie energii w budynku wpływ mają wszystkie przegrody budowlane. Ich udział w bilansie energetycznym jest zależny od powierzchni oraz izolacyjności cieplnej. Szacuje się, że straty ciepła przez przegrody przezroczyste wahają się w granicach $25 \div 40 \%$ wszystkich strat [1]. Jednakże nie generują one tylko strat ciepła, ale są także źródłem zysków bezpośrednich.

Parametrami charakteryzującymi jakość energetyczną oszklenia są współczynniki: przenikania ciepła okna $U_{w}$ oraz całkowitej przepuszczalności energii promieniowania słonecznego g. Na końcową wartość współczynnika przenikania ciepła okna ma wpływ budowa oszklenia, ramy oraz liniowy współczynnik przenikania ciepła opisujący mostek termiczny jako efekt połączenia oszklenia z ramką dystansową i ramą. Sposób obliczania zawarty jest w normie [2]. Należy pamiętać, iż o stratach ciepła okna decyduje cała konstrukcja okna, gdzie nie bez znaczenia jest także sposób montażu. Obecnie preferowany sposób to osadzenie okna w warstwie izolacji termicznej.

Podstawowe wymagania dla okien związane $\mathrm{z}$ energetyką budynku oraz koniecznością zapewnienia oświetlenia pomieszczeń światłem dziennym zawarte są w [3]. Dotyczą one m. in.: zapewnienia odpowiedniego stosunku powierzchni okien do powierzchni podłogi w zależności od przeznaczenia pomieszczenia, maksymalnych wartości współczynnika przenikania ciepła. Zawierają również zapis o zaprojektowaniu i wykonaniu budynku w taki sposób, aby ograniczyć ryzyko przegrzewania w okresie letnim, na co wpływ ma wartość współczynnika g dla przegród przezroczystych. Wartość ta dla okresu letniego nie może być większa niż 0,35 .

Można zatem stwierdzić, iż współcześnie projektowane przeszklenia muszą spełniać wzajemnie sprzeczne wymagania. $\mathrm{Z}$ jednej strony powinny gwarantować energooszczędną eksploatację budynku, a z drugiej zapewniać odpowiednie oświetlenie pomieszczeń. Szczególnie w budownictwie energooszczędnym od elementów przezroczystych wymaga się dużej elastyczności w zakresie parametrów związanych izolacyjnością cieplną i zdolnością do pozyskiwania energii cieplnej z promieniowania słonecznego. Niska wartość współczynnika przenikania ciepła $\mathrm{U}$, powinna być powiązana z wysoką wartością g, która z kolei musi być ograniczana sezonowo celem wyeliminowania przegrzewania budynku latem. W tym celu stosuje się rolety, żaluzje ograniczające dopływ promieniowania słonecznego, bądź zaawansowane technicznie oszklenia z powłokami ograniczającymi dopływ promieniowania, oszklenia fotochromowe itp. Rozwiązania te powinny zagwarantować jednakże prawidłowe oświetlenie pomieszczeń światłem dziennym. W [3] podane są współczynniki optyczne dla różnych rodzajów zasłon, oraz współczynniki redukcji promieniowania słonecznego w zależności od ich typu. Dla budownictwa niskoenergetycznego standardem stały się wymagania sprecyzowane przez NFOŚ w ramach programu wspierania budownictwa energooszczędnego znane pod skrótową nazwą NF 15 czy NF 40 [4]. 
Dla okien zgodnie z tymi wytycznymi wymagane wartości współczynnika przenikania muszą wynosić odpowiednio $\mathrm{U}<0,8(1,1) \mathrm{W} / \mathrm{m}^{2} \mathrm{~K}$, a dla tzw. okien aktywnych $\mathrm{U}<0,8$, natomiast $\mathrm{g} \geq 0,45$.

W niniejszym artykule autorzy podjęli próbę określenia wpływu wybranych parametrów oszklenia na zużycie energii w strefie o regulowanej temperaturze. Rozpatrywano także istotność zastosowania ruchomych żaluzji jako elementów zacieniających.

\section{Opis procedury badawczej}

\subsection{Opis programu symulacyjnego i założenia analiz}

Metoda badawcza przyjęta w pracy to badania numeryczne z wykorzystaniem programów Comfen, Window, Therm oraz EnergyPlus [5], [6]. Jest to zestaw narzędzi do oceny energetycznej okien oraz całych obiektów budowlanych. Za ich pomocą można modelować parametry energetyczne i optyczne okien, fasad przeszklonych oraz wyznaczać zużycie energii na potrzeby ogrzewania, chłodzenia, wentylacji, oświetlenia oraz zużycia ciepłej wody w budynkach. Ponadto dają możliwość modelowania oświetlenia pomieszczeń (wyznaczenie natężenia oświetlenia, iluminancji, olśnienia w wybranych punktach analizowanej strefy) z uwzględnieniem elementów zacieniających. Istnieje także możliwość określenia komfortu cieplnego w analizowanej strefie. Analizy bazują na wykorzystaniu metody MES w powiązaniu z implementacją równań empirycznych dla zjawisk nie opisanych w inny sposób. Obliczenia prowadzone są z godzinowym krokiem czasowym na bazie rzeczywistych danych klimatycznych.

W obliczeniach wykorzystano bazę danych klimatycznych dla miasta Katowice, stacja aktynometryczna - Chorzów.

Zewnętrzna fasada strefy jest jedyną powierzchnią, która jest wystawiona na działanie środowiska zewnętrznego. Wszystkie inne powierzchnie (sufit, podłoga, ściany wewnętrzne) są traktowane jako adiabatyczne.

Założenia przyjęte $w$ analizach:

- rodzaj budynku: mieszkalny,

- wymiary pomieszczenia: $4,0 \cdot 6,0 \cdot 2,8 \mathrm{~m}$,

- wymiary fasady szklanej: 4,0 $2,8 \mathrm{~m}$, podzielona na sześć jednakowych pól, o powierzchni całkowitej oszklenia $\mathrm{F}=9,363 \mathrm{~m}^{2}$,

- zyski ciepła od źródeł wewnętrznych przyjęto zgodnie z [7] dla budynku jednorodzinnego $\mathrm{q}_{\mathrm{int}}=6,8 \mathrm{~W} / \mathrm{m}^{2}$, od oświetlenia $\mathrm{q}_{\text {electr }}=5,0 \mathrm{~W} / \mathrm{m}^{2}$,

- strumień objętości powietrza wentylacyjnego $\mathrm{V}_{\text {inf }}=20 \mathrm{~m}^{3} / \mathrm{h} \cdot$ osoba,

- liczba osób: $\mathrm{n}=3$,

- nośnik energii: dla ogrzewania: gaz, dla chłodzenia: energia elektryczna,

- pomieszczenie ogrzewane jest do temperatury $20^{\circ} \mathrm{C}$, w okresie letnim chłodzenie jest uruchamiane, gdy temperatura przekroczy $24^{\circ} \mathrm{C}$. 
Dodatkowo przeanalizowano wpływ zastosowania ruchomych żaluzji, które umieszczono między szybami. Żaluzje wykonane w postaci cienkich lameli aluminiowych wpływają wyłącznie na transmisję promieniowania słonecznego, natomiast $\mathrm{z}$ uwagi na prawie zerowy opór cieplny nie stanowią elementu polepszającego wartość współczynnika przenikania ciepła całego okna. Żaluzje są sterowane temperaturą powietrza $\mathrm{w}$ pomieszczeniu i natężeniem promieniowania słonecznego na powierzchni szyby. Zasłaniają się, gdy zostaną osiągnięte wartości progowe powyższych wielkości, które przyjęto jako: temperaturę $\mathrm{w}$ pomieszczeniu $\mathrm{t}_{\mathrm{i}}=23^{\circ} \mathrm{C}$, natomiast natężenie całkowitego promieniowania słonecznego $\mathrm{I}_{\mathrm{c}}=100 \mathrm{~W} / \mathrm{m}^{2}$.

\subsection{Charakterystyka wariantów}

W celu określenia wpływu parametrów oszklenia na zużycie energii w wybranej strefie cieplnej przeprowadzono badania porównawcze. Rozpatrzono 4 warianty oszklenia. Wariant wyjściowy W0 spełnia wymagania izolacyjności termicznej stawiane przegrodom przezroczystym do 2014 r. Pozostałe warianty dobrano tak, aby odpowiadały aktualnym rozwiązaniom technicznym, spełniały aktualne wymagania izolacyjności termicznej [3], ale różniły się wartością współczynników: przenikania ciepła $\mathrm{U}$, całkowitej przepuszczalności energii promieniowania słonecznego g oraz przepuszczalności światła $\tau_{\text {vis. }} \mathrm{W}$ wariancie W0 przyjęto ramę drewnianą o współczynniku przenikania ciepła $\mathrm{U}_{\mathrm{f}}=2,27 \mathrm{~W} / \mathrm{m}^{2} \mathrm{~K}$, natomiast $\mathrm{w}$ pozostałych - ramę $\mathrm{PVC}$ o $\mathrm{U}_{\mathrm{f}}=1,0 \mathrm{~W} / \mathrm{m}^{2} \mathrm{~K}$. W tab. 1 zestawiono parametry dla poszczególnych wariantów.

Tabela 1. Charakterystyka analizowanych wariantów

Table 1. Characteristic of analyzed variants

\begin{tabular}{|c|c|c|c|c|}
\hline Wariant & $\begin{array}{l}\text { Schemat } \\
\text { zestawu } \\
\text { szybowego }\end{array}$ & $\begin{array}{c}\text { Współczynnik } \\
\text { g [-] }\end{array}$ & $\begin{array}{c}\text { Współczynnik } \\
\tau_{\text {vis }}[-]\end{array}$ & $\begin{array}{c}\text { Współczynnik } \\
\mathbf{U}_{\mathrm{w}}\left[\mathbf{W} / \mathbf{m}^{2} \mathbf{K}\right]\end{array}$ \\
\hline W0 & (4-18-4) & 0,79 & 0,82 & 2,71 \\
\hline W1 & $(4-18-4-18-4)$ & 0,71 & 0,74 & 1,64 \\
\hline W2 & $(6-18-4-18-6)$ & 0,60 & 0,72 & 0,65 \\
\hline W3 & $(4-18-4-18-6)$ & 0,34 & 0,43 & 0,71 \\
\hline
\end{tabular}


Wariant W0 to zestaw jednokomorowy złożony z szyb zwykłych, z wypełnieniem komory międzyszybowej powietrzem. Warianty W1 $\div$ W3 to zestawy trójszybowe, w których komory są wypełnione argonem. W1 to zestaw złożony z szyb zwykłych, W2 - szyby zwykłe z powłokami niskoemisyjnymi, natomiast W3 od strony zewnętrznej szkło $\mathrm{z}$ powłoką przeciwsłoneczną oraz od wewnętrznej strony z powłoką niskoemisyjną. W dalszych analizach dla wariantów $\mathrm{W} 0 \div \mathrm{W} 2$ przyjęto dodatkowo ruchome żaluzje $\left(\mathrm{W} 0 \_\dot{Z} \div \mathrm{W} 2 \_\dot{Z}\right)$.

\section{Wyniki badań i ich analiza}

W wyniku przeprowadzonych obliczeń uzyskano szereg wyników obrazujących zachowanie się modelu pod obciążeniem cieplnym wywołanym klimatem zewnętrznym. $Z$ punktu widzenia celu jakiemu podporządkowane były badania, uzyskane wyniki obliczeń, dla założeń opisanych w rozdziale 2 , przedstawiają wykresy na rys. $1 \div 4$. Przyjęto, iż budowa zestawu szybowego w wariancie W3 stanowi dostateczne rozwiązanie zabezpieczające przed przegrzewaniem, dlatego nie zastosowano w nim żaluzji. Dla porównania na wykresach wprowadzono wartości uzyskane dla wariantu W3.

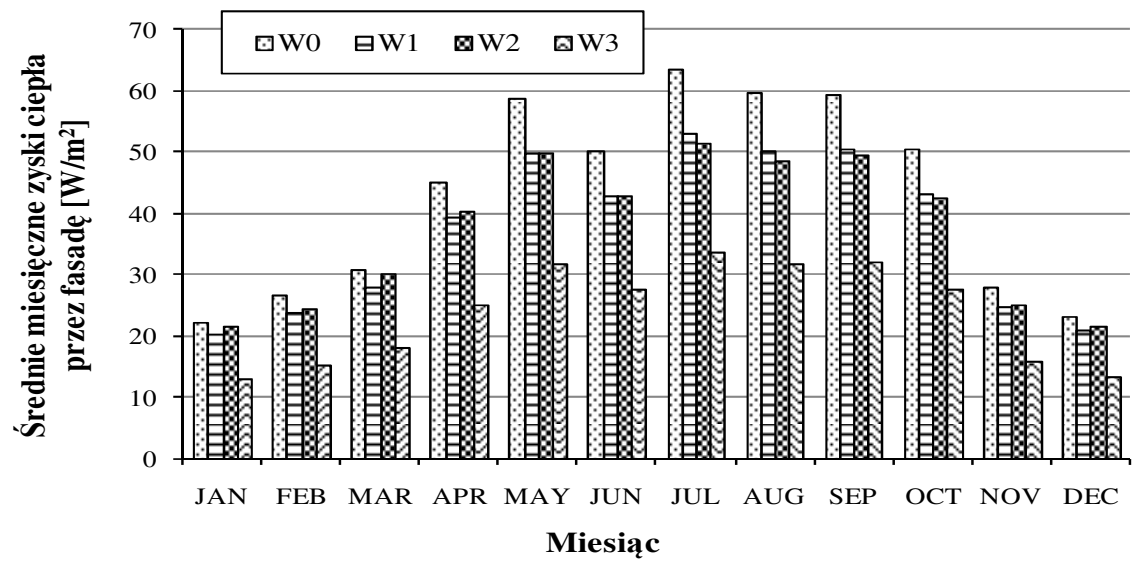

Rys. 1. Średnie miesięczne zyski ciepła przez fasadę dla poszczególnych wariantów bez żaluzji w przeliczeniu na $\mathrm{m}^{2}$ powierzchni podłogi

Fig. 1. Average monthly heat gains via the façade for individual variants without shutters - per $1 \mathrm{~m}^{2}$ of the floor

Najwyższymi wartościami średnich miesięcznych zysków ciepła przez fasadę charakteryzuje się wariant W0. Nie spełnia on jednak aktualnych wymagań w zakresie izolacyjności termicznej. Najniższe wartości uzyskano dla wariantu W3. Warianty W1 oraz W2 charakteryzują się porównywalnymi wartościami miesięcznych zysków ciepła. Zastosowanie ruchomych żaluzji wpływa na zmniejszenie miesięcznych zysków ciepła w porównaniu z wariantami bez nich. 
Najwyższe wartości średnich miesięcznych zysków ciepła przez fasadę uzyskano dla wariantu W2_Ż. W wariancie W3 pomimo braku żaluzji występują najniższe zyski ciepła.

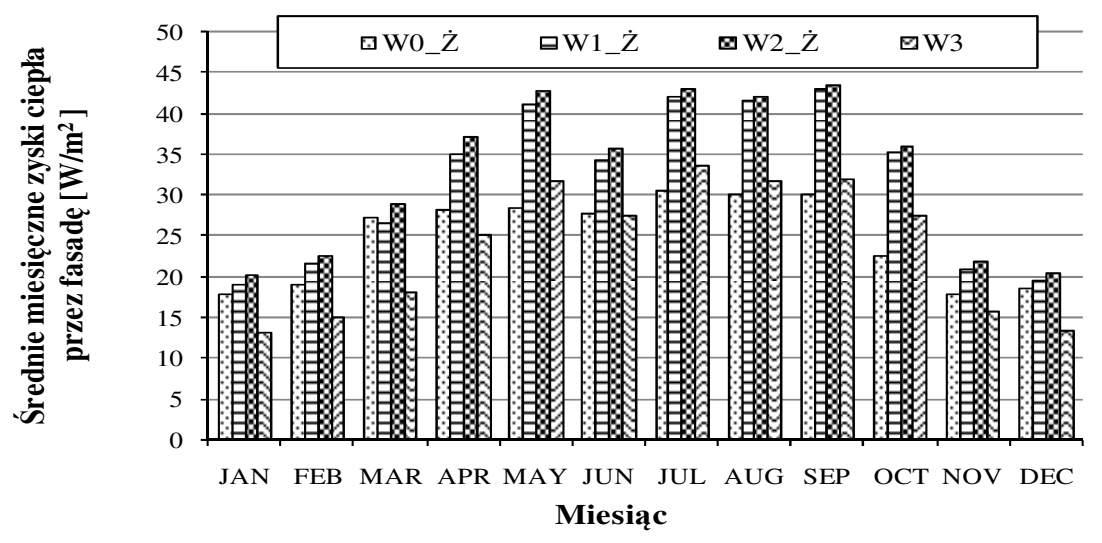

Rys. 2. Średnie miesięczne zyski ciepła przez fasadę dla poszczególnych wariantów $\mathrm{z}$ uwzględnieniem żaluzji w przeliczeniu na $\mathrm{m}^{2}$ powierzchni podłogi

Fig. 2. Average monthly heat gains via the façade for individual variants with shutters - per $1 \mathrm{~m}^{2}$ of the floor

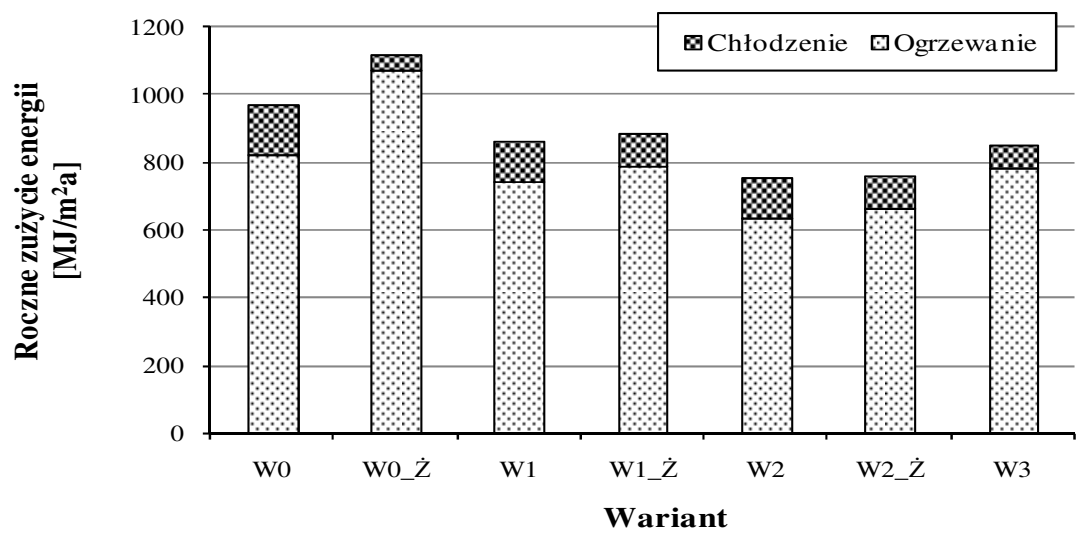

Rys. 3. Roczne zużycie energii dla poszczególnych wariantów w przeliczeniu na $\mathrm{m}^{2}$ powierzchni podłogi

Fig. 3. Annual energy consumption for individual variants per $1 \mathrm{~m}^{2}$ of the floor

Analizując zużycie energii dla wszystkich wariantów, łącznie dla sezonu grzewczego i chłodniczego, zaobserwowano poniższe prawidłowości:

- najniższe zużycie energii na cele ogrzewania występuje dla wariantu W2, najwyższe dla W0_Ż; 
- najniższe zużycie energii na cele chłodzenia występuje dla W0_Ż, najwyższe dla W0;

- najniższe zużycie energii na cele oświetlenia dla W0, najwyższe dla W3.

$\mathrm{Na}$ rys. 4. przedstawiono wykres zużycia energii w sezonie grzewczym (s_g, XI $\div$ IV) oraz chłodniczym (s_ch, V $\div$ X) dla wariantów z i bez żaluzji. Dla wariantów z żaluzjami w sezonie letnim (s_ch) obserwujemy mniejsze zapotrzebowanie na chłodzenie, ale wyższe na grzanie niż dla wariantów bez żaluzji. Natomiast w sezonie zimowym (s_g) warianty te charakteryzują się wyższym zapotrzebowaniem na ogrzewanie niż rozwiązania bez żaluzji. Zdaniem autorów należałoby zmienić algorytm sterowania żaluzjami w zależności od sezonu.

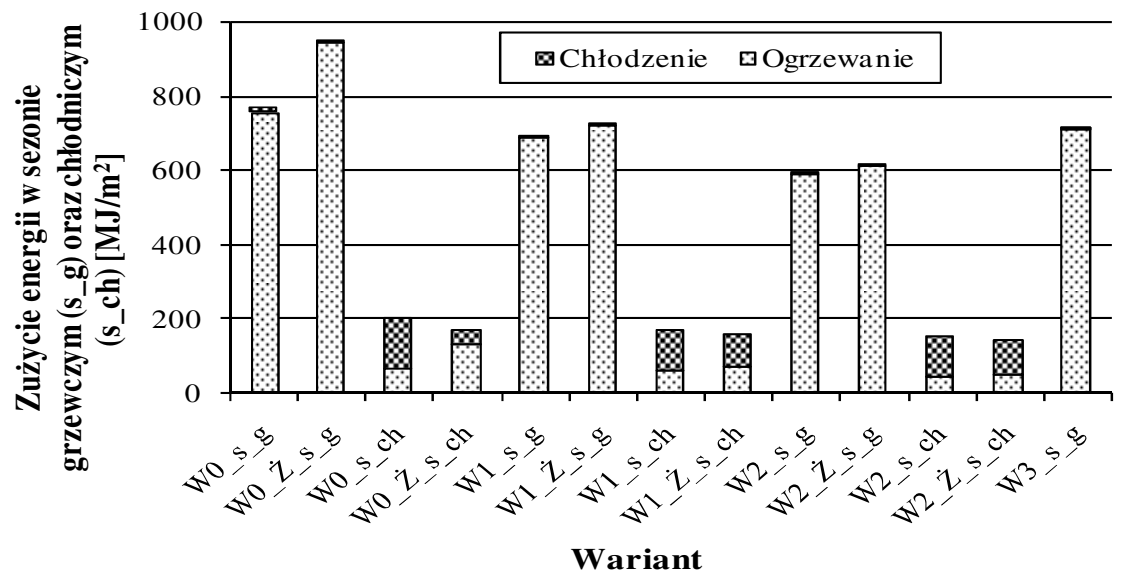

Rys. 4. Zużycie energii w sezonie grzewczym (s_g) i chłodniczym (s_ch) dla poszczególnych wariantów $\mathrm{z}$ oraz bez żaluzji w przeliczeniu na $\mathrm{m}^{2}$ powierzchni podłogi

Fig. 4. Energy consumption in the heating season (s_g) and cooling (s_ch) for individual variants with and without shutters per $1 \mathrm{~m}^{2}$ of the floor

\section{Podsumowanie}

Zastosowanie żaluzji powoduje zwiększenie zużycia energii dla ogrzewania i oświetlenia, natomiast zmniejszenie zużycia energii na chłodzenie oraz wentylację, zarówno w sezonie grzewczym jak i chłodniczym w porównaniu z wariantami bez żaluzji. Najbardziej korzystnymi z punktu widzenia miesięcznych zysków ciepła przez fasadę oraz zużycia energii w roku wydają się być rozwiązania W2 oraz W2_Ż czyli zestaw trójszybowy, w których komory są wypełnione argonem, szyby zwykłe z powłokami niskoemisyjnymi, bez lub z żaluzjami. Należy również zwrócić uwagę na względnie niewielką różnicę w rocznym zużyciu energii pomiędzy wariantami W0 i W3. Jest to szczególnie interesujące, bowiem różnią się one istotnie izolacyjnością termiczną $\left(2,71 \mathrm{vs} .0,71 \mathrm{~W} / \mathrm{m}^{2} \mathrm{~K}\right)$. Wpływają na to zyski ciepła przez fasadę, które dla wariantu W0 są najwyższe. 


\section{Literatura}

[1] Laskowski L.: Ochrona cieplna i charakterystyka energetyczna budynków, Oficyna Wydawnicza Politechniki Warszawskiej, Warszawa 2008.

[2] EN ISO 10077-1.: Cieplne właściwości użytkowe okien, drzwi i żaluzji - obliczanie współczynnika przenikania ciepła. Cz. 1.: Postanowienia ogólne.

[3] Rozporządzenie MIiR z dn. 17.07.2015 r. w sprawie warunków technicznych, jakim powinny odpowiadać budynki i ich usytuowanie, Dz.U. z 2015 r. poz. 1422.

[4] www.nfosigw.gov.pl/.../gfx/nfosigw/pl/.../wytyczne_do_pp.pdf \{dostęp 10.05.2016 r.\}.

[5] http://bigladdersoftware.com/epx/docs/8-0/input-output-reference/page-094.html \{dostęp 10.05.2016 r. \}.

[6] https://windows.lbl.gov/software/comfen/comfen.html \{dostęp 10.05.2016 r.\}.

[7] Rozporządzenie MIiR z dn. 18.03.2015 r. w sprawie metodologii wyznaczania charakterystyki energetycznej budynku lub części budynku..., Dz. U. z 2015 r. poz. 376.

\section{IMPACT OF GLAZING PARAMETERS ON ENERGY CONSUMPTION IN A ZONE WITH ADJUSTABLE TEMPERATURE}

\section{S u m m a r y}

The goal of this paper was to determine the impact of glazing parameters on energy consumption in selected thermal zone. A room with parameters of a living room and kitchenette was selected as such a zone. Such zones are frequently used in architectural solutions for contemporary energy-saving detached buildings. The south façade is glazed in order to gather thermal energy from solar radiation. The dimensions of this room are as follows: $4.0 \times 6.0 \mathrm{~m}$, height of $2.8 \mathrm{~m}$. We chose the numerical method for testing - Comfen, Window, Therm and EnergyPlus software. 4 variants were used in the analysis. The reference point was the glazed façade made of single chamber pane set filled with air. Other variants were selected in such a way that they corresponded to modern solutions of pane sets assigned for low-energy buildings. They meet current requirements of thermal insulating power [3] but they have different values of the following coefficients: heat transfer [U], total permeability of solar radiation energy [g] and light transmittance $\left[\tau_{\text {vis }}\right]$. They are sets with three glasses and chambers filled with argon and the panes are covered with selective coats (see Table 1). Additionally, the impact of movable shutters was tested. From the point of view of monthly heat gains via the façade and annual energy consumption it seems that the most advantageous are W2 and W2_Ż solutions - that is the set with three panes and chambers filled with argon, the panes are covered by low emission coats without or with shutters.

Keywords: total solar radiation energy permeability coefficient, solar heat gain, pane sets, low emissions coats, energy saving building

DOI:10.7862/rb.2016.181

Przestano do redakcji: $30.06 .2016 r$.

Przyjęto do druku: 30.11.2016 r. 